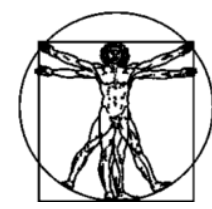

\title{
ВЛИЯНИЕ ОСТЕОАРТРОЗА КОЛЕННОГО СУСТАВА НА БИОМЕХАНИЧЕСКИЕ ПОКАЗАТЕЛИ ТАЗОБЕДРЕННОГО СУСТАВА
}

\author{
Р.О. Солодилов, С.И. Логинов
}

Научно-исследовательская лаборатория биомеханики и кинезиологии Сургутского государственного университета, Сургут, проспект Ленина, 1, e-mail: goodroman@mail.ru, logsi@list.ru

\begin{abstract}
Аннотация. Цифровая визуализация биомеханических исследований костномышечной системы с помощью безмаркерного захвата движений при остеоартрозах весьма актуальна. Целью исследования является установление особенностей влияния остеоартроза коленного сустава на биомеханические показатели тазобедренного сустава у людей в возрасте 40-65 лет. В исследовании приняло участие 42 человека без симптоматических признаков остеоартроза коленного сустава (контрольная группа) и 31 человек с билатеральным остеоартрозом коленного сустава (экспериментальная группа) в возрасте 40-65 лет. Методом безмаркерного захвата движений зафиксированы значимые различия между группами контрольной и экспериментальной в кинематике тазобедренных суставов и во временных показателях, полученных при проведении теста $(p \leq 0,01)$. Для выполнения теста в экспериментальной группе требуется $1,94 \pm 0,09$ с $(X \pm S D)$, а в контрольной группе - лишь $1,72 \pm 0,07$ с ( $p \leq 0,01)$. Существенные различия зафиксированы в фразу опоры: у экспериментальной группы 0,78 $\pm 0,03 \mathrm{c}$, у контрольной $-0,62 \pm 0,03 \mathrm{c}(p \leq 0,01)$. Во второй и третьей фазах существенных различий между контрольной и экспериментальной группами не обнаружено. Показано, что при выполнении теста люди, страдающие остеоартрозом коленного сустава, имеют бозльшую флексию бедра (на $21 \%$ ), чем люди без остеоартроза коленного сустава. В контрольной и экспериментальной группах существенные различия найдены между доминантными нижними конечностями. В экспериментальной группе тазобедренные суставы доминантных конечностей находились в положении бозльшей наружной ротации (на $25 \%$ по сравнению с контрольной группой. Также обнаружено, что в конце теста тазобедренные суставы доминантных конечностей испытуемых экспериментальной группы находились в менее отведенном положении (на 49 \%), чем в контрольной. Существенные различия между тазобедренными суставами доминантной и недоминантной конечностей зафиксированы внутри контрольной группы, т.е. недоминантная конечность имела бозльшие моменты наружной ротации (на $31 \%$ ), чем доминантная конечность $(p \leq 0,01)$. Данные различия могут обозначать, что люди, страдающие остеоартрозом коленного сустава, претерпевают гораздо большее напряжение в хрящах тазобедренного сустава, что потенциально может привести к развитию и/или прогрессированию остеоартроза в тазобедренном суставе.
\end{abstract}

Ключевые слова: биомеханика, остеоартроз, коленный сустав, тазобедренный сустав, безмаркерная система захвата движения.

(С) Солодилов Р.О., Логинов С.И., 2015

Солодилов Роман Олегович, аспирант, младший научный сотрудник научно-исследовательской лаборатории биомеханики и кинезиологии Сургутского государственного университета, Сургут Логинов Сергей Иванович, д.б.н., профессор научно-исследовательской лаборатории биомеханики и кинезиологии Сургутского государственного университета, Сургут 


\section{ВВЕДЕНИЕ}

На сегодняшний день остеоартроз является одним из самых распространенных заболеваний как в России, так и за рубежом. По данным широкомасштабного исследования, проведенного в семи городах бывшего СССР, остеоартроз был выявлен у 6,43 \% обследованных [1]. Показатель заболеваемости остеоартроза среди населения России за 14 лет в период с 2001 по 2014 г. увеличился с 1574,4 до 2720 на 100 тысяч населения. Количество зарегистрированных в стране людей, страдающих остеоартрозом, превышает 3,1 миллиона человек, и с каждым годом диагностируется свыше 600 тысяч новых случаев [2]. В целом в различных странах распространенность остеоартроза широко варьируется. В США более 26,9 миллионов человек старше 25 лет страдают от этого недуга, что составляет примерно 8,4\% населения $[12,25]$. Остеоартроз коррелирует с возрастом и наиболее распространен у людей старше 25 лет [19]. Чаще всего под пагубное воздействие остеоартроза попадает именно коленный сустав. Он состоит из трех частей: большеберцово-бедренный (тибиофеморальный) отдел, который имеет медиальную и латеральную стороны, и надколенно-бедренный (пателлофеморальный) отдел. Наиболее подверженной воздействию остеоартроза является медиальная сторона тибиофеморального отдела, которая поражается в 75 \% случаев. Пателлофеморальный отдел поражается в 48 \% случаев, а латеральная сторона тибиофеморального отдела - в $26 \%$ случаев [3, 4]. В то же время именно при поражении пателлофеморального отдела риск получения инвалидности в несколько раз выше, чем при поражении тибиофеморальных отделов [21]. Остеоартроз пателлофеморального отдела более широко распространен у людей старше 55 лет. У $24 \%$ женщин и 15,4\% мужчин данного возраста диагностируется остеоартроз пателлофеморального отдела коленного сустава $[9,21]$.

Этиология остеоартроза зависит от физиологических, биохимических и механических факторов, каждый из которых является весьма значительным [10, 24]. При проведении клинического исследования Huberti и Hayes [16] выявили, что увеличенная коленная варусная или вальгусная деформация приводит к увеличению локальной суставной нагрузки на коленный сустав. Высокое суставное давление - это результат развития и прогрессирования остеоартроза пателлофеморального отдела коленного сустава [7,8]. Суставная нагрузка на пателлофеморальный отдел коленного сустава усиливается во время принудительного сгибания колена, так как противодействующая сила пателлофеморального отдела достигает своего пика при выполнении действий, которые включают в себя принудительное сокращение четырехглавой мышцы бедра в тот момент, когда коленный сустав максимально согнут $[15,27]$.

Из-за тенденции роста количества случаев остеоартроза среди взрослого населения требуется развитие новых методов диагностики заболеваний опорнодвигательного аппарата, в частности таких, как метод безмаркерного захвата движений, который благодаря высокой визуализации можно использовать для оценки и диагностики поражений в суставах у людей, страдающих остеоартрозом коленного сустава. Тогда при проведении физической реабилитации остеоартроза врач будет опираться не только на знания анатомии и физиологии сустава, но и на данные о кинематике коленного сустава и опорно-двигательного аппарата в целом.

Целью данного исследования является установление особенностей влияния остеоартроза коленного сустава на биомеханические показатели тазобедренного сустава у людей в возрасте 40-65 лет при помощи метода безмаркерного захвата движений. 


\section{МЕТОДЫ И ОРГАНИЗАЦИЯ ИССЛЕДОВАНИЯ}

Контингент. В исследовании приняли участие 42 здоровых человека без видимых симптоматических признаков остеоартроза коленного сустава (контрольная группа) и 31 человек с билатеральным остеоартрозом коленного сустава пателлофеморального отдела (экспериментальная группа) в возрасте 40-65 лет (табл. 1). У испытуемых экспериментальной группы были первая и вторая степени остеоартроза. Все испытуемые дали письменное информированное согласие на участие в исследовании.

После учета критериев включения в исследование и исключения из него (табл. 2) в контрольной группе осталось тридцать человек, в экспериментальной группе - двадцать пять (табл. 3).

Демографические данные участников исследования

\begin{tabular}{|l|c|c|c|}
\hline \multicolumn{1}{|c|}{ Значение } & $\begin{array}{c}\text { Общее } \\
\text { количество }\end{array}$ & $\begin{array}{c}\text { Экспериментальная } \\
\text { группа }\end{array}$ & $\begin{array}{c}\text { Контрольная } \\
\text { группа }\end{array}$ \\
\hline Количество & 73 & 31 & 42 \\
\hline Возраст & $40-65$ & $40-65$ & $40-65$ \\
\hline Средний возраст $($ mean $\pm S D)$ & $53,2(7,0)$ & $56,0(6,4)$ & $51,0(6,7)$ \\
\hline Пол: & 22 & 7 & 15 \\
мужчины & 51 & 24 & 27 \\
женщины & $166,5(5,9)$ & $166,5(5,4)$ & $166,5(6,3)$ \\
\hline Рост, см $($ mеап $\pm S D)$ & $68,3(8,9)$ & $69,2(8,1)$ & $67,7(9,5)$ \\
\hline Масса тела, кг $($ mean $\pm S D)$ & & & \\
\hline
\end{tabular}

Таблий 2

Критерии включения и исключения

\begin{tabular}{|l|c|c|}
\hline \multicolumn{1}{|c|}{ Характеристика } & \multicolumn{1}{|c|}{ Экспериментальная группа } & Контрольная группа \\
\hline \multicolumn{1}{|c|}{ Критерии включения } & + \\
\hline Возраст 40-65 лет & \multicolumn{1}{|c|}{+} & + \\
\hline Диапазон сгибания колена 120 & + & + \\
\hline $\begin{array}{l}\text { Способность самостоятельно } \\
\text { передвигаться на расстояние более } \\
15 \text { м без вспомогательных устройств }\end{array}$ & + & + \\
\hline $\begin{array}{l}\text { Способность самостоятельно вставать } \\
\text { со стандартного стула не менее 5 раз } \\
\text { без использования рук* }\end{array}$ & + & - \\
\hline $\begin{array}{l}\text { Наличие болевых ощущений в коленях } \\
\text { более одного года }\end{array}$ & \multicolumn{1}{|c|}{+} \\
\hline Билатеральная боль в коленях & + & + \\
\hline \multicolumn{1}{|c|}{ Критерии исключения } & + \\
\hline $\begin{array}{l}\text { Неврологические заболевания или } \\
\text { заболевания опорно-двигательного } \\
\text { аппарата, которые могут повлиять на } \\
\text { результаты теста }\end{array}$ & + & + \\
\hline $\begin{array}{l}\text { Заболевания разгибательного } \\
\text { механизма колена }\end{array}$ & + & + \\
\hline Беременность & + & + \\
\hline $\begin{array}{l}\text { Кортикостероидные инъекции в } \\
\text { колено, за последние три месяца }\end{array}$ & + & + \\
\hline
\end{tabular}

Примечание: * высота стандартного стула -44 см. 
Таблица 3

Сравнительные данные участников, включенных в исследование и исключенных из него

\begin{tabular}{|c|c|c|c|c|}
\hline Показатель & $\begin{array}{c}\text { Экспериментальная } \\
\text { группа: вкл. }\end{array}$ & $\begin{array}{c}\text { Экспериментальная } \\
\text { группа: искл. }\end{array}$ & $\begin{array}{c}\text { Контрольная } \\
\text { группа: вкл. }\end{array}$ & $\begin{array}{l}\text { Контрольная } \\
\text { группа: искл. }\end{array}$ \\
\hline Количество & 25 & 6 & 30 & 12 \\
\hline Возраст & $42-65$ & $42-64$ & $41-65$ & $40-61$ \\
\hline $\begin{array}{l}\text { Средний возраст } \\
(\text { mean } \pm S D)\end{array}$ & $56,1(5,8)$ & $55,8(9,2)$ & $51,6(7,1)$ & $49,6(5,8)$ \\
\hline $\begin{array}{l}\text { Пол: } \\
\text { мужчины } \\
\text { женщины }\end{array}$ & $\begin{array}{c}7 \\
18\end{array}$ & $\begin{array}{l}0 \\
6\end{array}$ & $\begin{array}{l}11 \\
19\end{array}$ & $\begin{array}{l}4 \\
8\end{array}$ \\
\hline $\begin{array}{l}\text { Рост, м } \\
(\text { mean } \pm S D)\end{array}$ & $167,0(5,5)$ & $164,5(4,6)$ & $166,6(6,0)$ & $166,3(7,2)$ \\
\hline $\begin{array}{l}\text { Вес, кг } \\
(\text { mean } \pm S D)\end{array}$ & $69,7(8,8)$ & $67,2(3,5)$ & $67,5(9,4)$ & $68,1(10,2)$ \\
\hline
\end{tabular}

Методы исследования. Между участниками, исключенными из протокола исследования, и теми, кто остался и принял участие в работе, другие отличия отсутствовали. В начале эксперимента были выполнены следующие антропометрические измерения: рост, вес, высота коленного сустава.

Доминантность нижней конечности была установлена при помощи трех методов определения ведущей ноги. Испытуемым предлагалось выполнить следующие тесты: закидывание ноги на ногу (сверху оказывается функционально преобладающая нога), шаг вперед и шаг назад (нога, выполняющая движение первой, считается ведущей), прыжок в длину (ведущая нога является толчковой). Доминантной считалась конечность, которая была ведущей при выполнении двух и более из трех тестовых заданий.

Биомеханический анализ вставания был проведен с использованием трёх безмаркерных сенсорных контроллеров «Microsoft Kinect v.2», оснащенных системой захвата движения и программного обеспечения «Brekel Pro Body». Данный безмаркерный сенсорный контроллер зарекомендовал себя как надежное средство получения достоверных показателей $[13,20]$. Сенсоры располагались на триподе, высота которого была отрегулирована на $80 \mathrm{~cm}$, расстояние от сенсоров до стула составляло $210 \mathrm{~cm}$. Безмаркерные сенсорные контроллеры были установлены во фронтальной и сагиттальной плоскостях по отношению к испытуемому.

Участники исследования вставали с табурета, высота которого была отрегулирована на уровне $110 \%$ от высоты коленей, руки в скрещенном положении на уровне груди. Колени испытуемых были поставлены под $90^{\circ}$, положение ступней было естественным. Тест выполнялся без обуви. Для более точной фиксации времени подъема к сиденью стула был прикреплен контактный выключатель. Скорость выполнения теста выбиралась испытуемыми. Участники исследования выполняли тест в три подхода. Весь цикл движения был разбит на три фазы, которые были описаны Schenkman и коллегами [23]: фаза I - фаза опоры; фаза II - фаза передачи импульса; фаза III - фаза выпрямления. Фазы в свою очередь были разбиты на четыре события $\left(t^{1}-t^{4}\right): t^{1}-$ старт (туловище отклоняется на $1^{\circ}$ или более), $t^{2}-$ вставание (контактные выключатели на стуле выключаются), $t^{3}$ - максимальное сгибание голеностопного сустава доминантной конечности, $t^{4}-$ конец (угловая скорость тазобедренного сустава равняется 0 град/с) (рис. 1). Начало движения было определено как момент, когда торс в сагиттальной плоскости отклонялся на один градус или более. Подъем определялся как момент, когда контактные выключатели отключались, обозначая тем самым, что контакт между musculus gluteus испытуемого и поверхностью табурета отсутствует. 


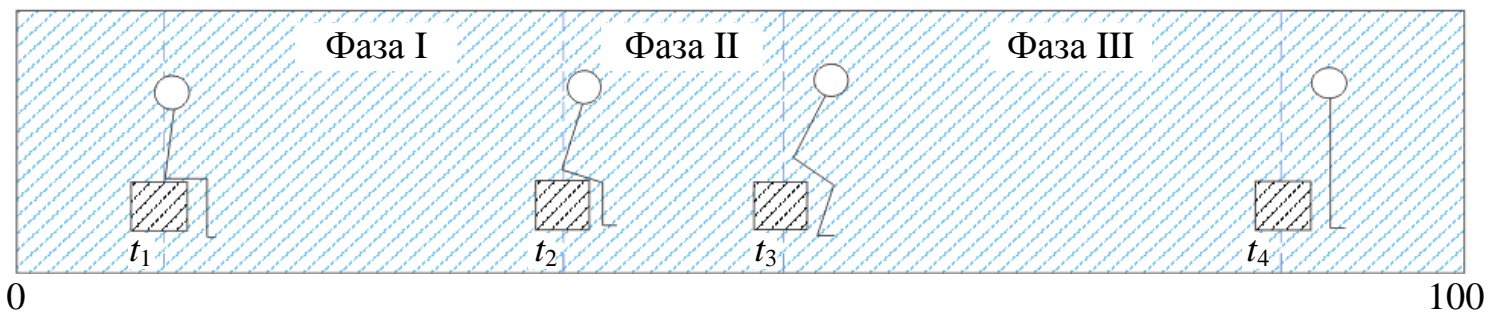

Время выполнения, \%

Рис. 1. Фазы вставания

Конец движения определяли как момент, когда угловая скорость разгибания бедра равнялась 0 град/с. Цикл движения был нормализован следующим образом: $0 \%$ начало теста, $100 \%$ - конец теста (см. рис. 1).

Углы тазобедренных суставов были подсчитаны при помощи программного обеспечения «Brekel Pro Body». Для определения кинематических показателей данное программное обеспечение использует уравнения решения обратной задачи динамики сферического движения. Захват движения происходит в трех ортогональных плоскостях (сагиттальной, фронтальной и поперечной). Данные о каждом суставе сохраняются в формате Comma-Separated Values (csv) для каждой из трех степеней свободы XYZ.

Зависимые переменные включали в себя углы тазобедренных суставов: максимальные и минимальные моменты, углы в начале и конце теста, углы в начале выполнения подъема. Биомеханические переменные были оценены в трёх анатомических плоскостях движения. Статистический анализ также был проведен между доминантной и недоминантной нижними конечностями.

Статистический анализ был проведен при помощи программного пакета Statistica 10 (StatSoft, Inc., США). Рассчитывали среднее значение $<X>$ и стандартное отклонение $<S D>$ для коленного и тазобедренного суставов: максимальные и минимальные угловые моменты, углы в начале и конце теста и углы в начале вставания. Данные групп были усреднены и стандартизированы. Ввиду большого количества сравнений уровень статистической значимости был установлен на $p \leq 0,01$.

\section{РЕЗУЛЬТАТЫ ИССЛЕДОВАНИЯ}

Временные характеристики. На выполнение теста экспериментальной группе потребовалось в среднем 1,94 $\pm 0,09$ с, что существенно отличается от времени, которое затратили на выполнение аналогичного теста испытуемые контрольной группы, 1,72 $(0,07)$ с (t-test, $p \leq 0,01)$. При выполнении фазы опоры экспериментальная группа затратила $0,78 \pm 0,03 \mathrm{c}$, что достоверно больше, чем контрольная $0,62 \pm 0,03 \mathrm{c}$ (t-test, $p \leq 0,01)$. При выполнении второй и третей фаз существенных различий между контрольной и экспериментальной группами выявлено не было. При выполнении второй фазы движения контрольная группа затратила $0,21 \pm 0,02$ с, в то время как экспериментальной группе потребовалось $0,23 \pm 0,03$ с (t-test, $p=0,0105)$. При выполнении третьей фазы движения контрольная группа затратила $0,88 \pm 0,04 \mathrm{c}$, экспериментальная группа - 0,92 $\pm 0,06$ с (t-test, $p=0,0358)$ (рис. 2).

Кинематика. При статистическом анализе кинематики тазобедренного сустава были зафиксированы существенные различия между контрольной и экспериментальной группами (t-test, $p \leq 0,01)$ (табл. 4). В сагиттальной плоскости тазобедренного сустава испытуемые экспериментальной группы в конце теста и в положении с минимальным значением угла, которое было зафиксировано при выполнении задания, имели меньшие моменты экстензии по сравнению с контрольной (рис. 3). Помимо этого существенные различия были зафиксированы и в кинематике тазобедренного сустава доминантных конечностей между группами контрольной и экспериментальной. 




Рис. 2. Временные характеристики затраченного времени на выполнение фаз вставания. I - фазы опоры; II - фазы передачи импульса; III - фазы выпрямления; * - достоверные различия между группами контрольной и экспериментальной $(t$-test, $p \leq 0,01)$

Таблииа 4

Кинематические данные углов тазобедренных суставов (в град). Сагиттальная (сгибание), фронтальная (отведение) и поперечная (ротация) плоскости. Углы выражены в средних значениях (стандартные отклонения)

\begin{tabular}{|c|c|c|c|}
\hline Событие & Плоскость & $\begin{array}{l}\text { Контрольная группа } \\
\text { (Д/НД), mean, }(S D)\end{array}$ & $\begin{array}{c}\text { Экспериментальная группа } \\
\text { (Д/НД), mean, }(S D)\end{array}$ \\
\hline \multirow[t]{3}{*}{ Начало } & Сагиттальная & $57,3(3,1) / 56,8(2,3)$ & $57,7(4,2) / 57,5(4,3)$ \\
\hline & Фронтальная & $9,3(2,5) / 8,3(2,2)$ & $8,9(3,6) / 8,1(4,0)$ \\
\hline & Поперечная & $7,7(2,7)^{\mathrm{B}} / 11,5(3,7)^{6}$ & $10,9(3,8)^{\mathrm{B}} / 11,0(3,3)$ \\
\hline \multirow[t]{3}{*}{ Подъем } & Сагиттальная & $73,3(5,2) / 72,4(5,3)$ & $72,2(5,4) / 71,5(5,5)$ \\
\hline & Фронтальная & $9,5(2,5) / 8,3(3,1)$ & $9,1(2,4) / 8,7(2,2)$ \\
\hline & Поперечная & $7,5(3,2)^{\mathrm{B}} / 11,8(4,1)^{6}$ & $11,8(2,9)^{\mathrm{B}} / 12,3(3,0)$ \\
\hline \multirow[t]{3}{*}{ Конец } & Сагиттальная & $8,5(3,2) / 8,3(2,6)^{\mathrm{a}}$ & $12,4(3,1) / 11,3(3,3)^{\mathrm{a}}$ \\
\hline & Фронтальная & $4,7(2,2)^{\mathrm{B}} / 4,1(2,2)$ & $2,4(2,2)^{\mathrm{B}} / 3,3(2,4)$ \\
\hline & Поперечная & $11,9(3,6)^{\mathrm{B}} / 16,2(3,8)^{6}$ & $14,3(4,1)^{\mathrm{B}} / 15,6(4,7)$ \\
\hline \multirow{3}{*}{$\begin{array}{c}\text { Максимальная } \\
\text { угловая позиция } \\
\text { сустава }\end{array}$} & Сагиттальная & $75,5(4,7) / 74,6(4,2)$ & $74,0(5,3) / 73,3(5,5)$ \\
\hline & Фронтальная & $10,7(2,5) / 9,7(2,7)$ & $9,9(3,4) / 10,0(4,0)$ \\
\hline & Поперечная & $13,5(3,2)^{\mathrm{B}} / 18,4(2,4)^{6}$ & $16,3(4,3)^{\mathrm{B}} / 17,5(4,6)$ \\
\hline \multirow{3}{*}{$\begin{array}{c}\text { Минимальная } \\
\text { угловая позиция } \\
\text { сустава }\end{array}$} & Сагиттальная & $8,5(3,2) / 8,3(2,6)^{\mathrm{a}}$ & $12,4(3,1) / 11,3(3,3)^{\mathrm{a}}$ \\
\hline & Фронтальная & $4,7(2,2)^{\mathrm{B}} / 4,1(2,2)$ & $1,8(2,2)^{\mathrm{B}} / 3,3(2,6)$ \\
\hline & Поперечная & $7,4(2,6)^{\mathrm{B}} / 11,5(5,1)^{6}$ & $10,9(4,4)^{\mathrm{B}} / 11,0(4,6)$ \\
\hline
\end{tabular}

Примечание: Д/НД - доминантная/недоминантная нижняя конечность; mean - среднее значение; $S D$ - стандартное отклонение; ${ }^{\text {a }}$ - статистически значимое различие между группами $p \leq 0,01 ;{ }^{6}$ - статистически значимое различие между доминантной и недоминантной конечностями $p \leq 0,01 ;{ }^{\text {в }}$ - статистически значимое различие между доминантной или недоминантной конечностями в контрольной и экспериментальной группах $p \leq 0,01$ 


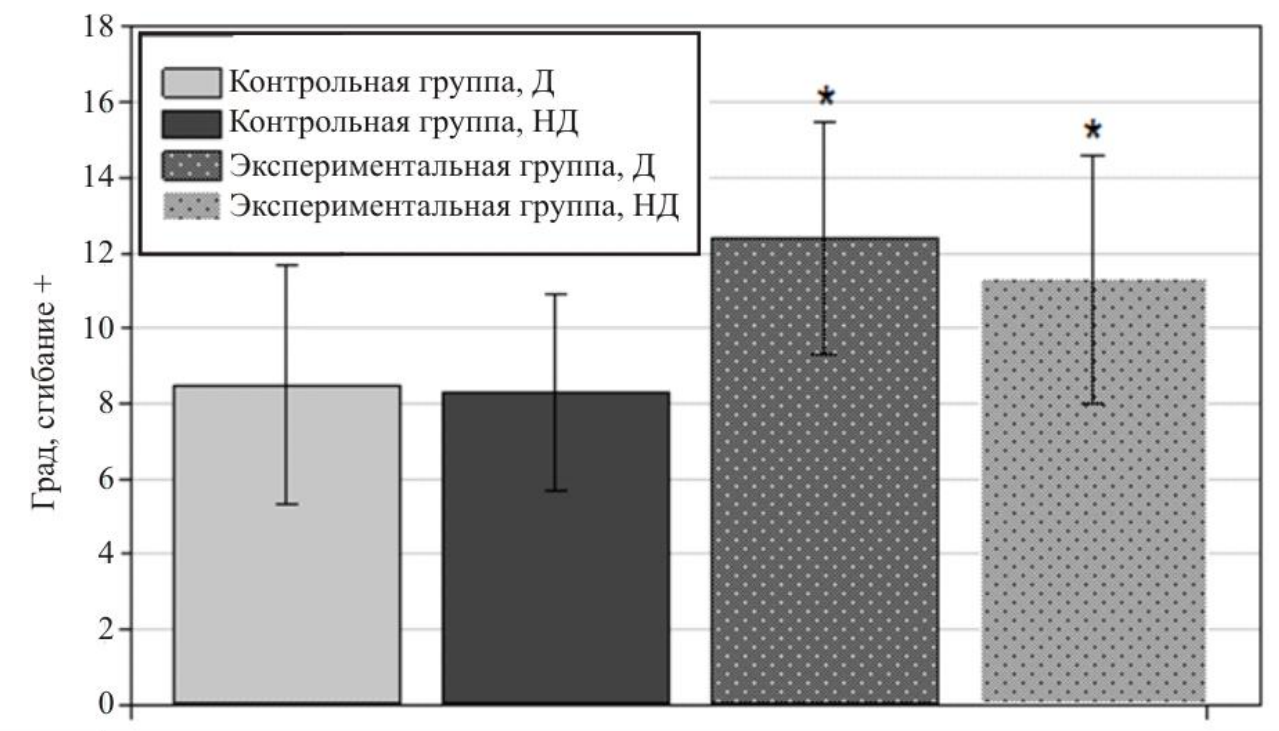

Рис. 3. Угловые позиции тазобедренных суставов в конце теста и при минимальном угловом положении, которое было зафиксировано при выполнении тестового задания, в сагиттальной плоскости. * - представлены достоверные различия между группами, $p \leq 0,01$. Д - доминантная нижняя конечность; НД - недоминантная нижняя конечность

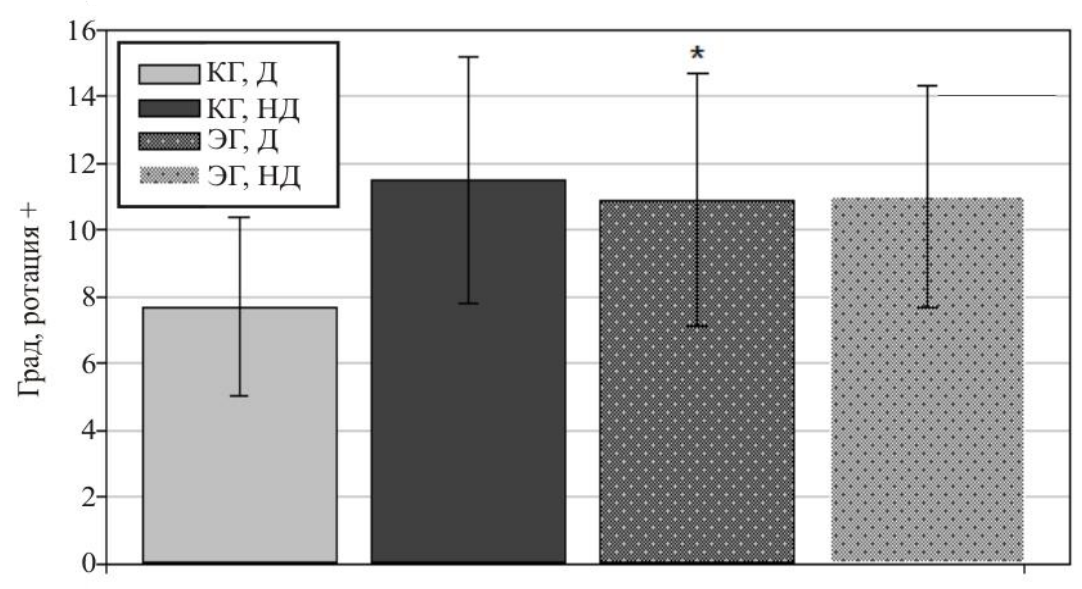

$a$

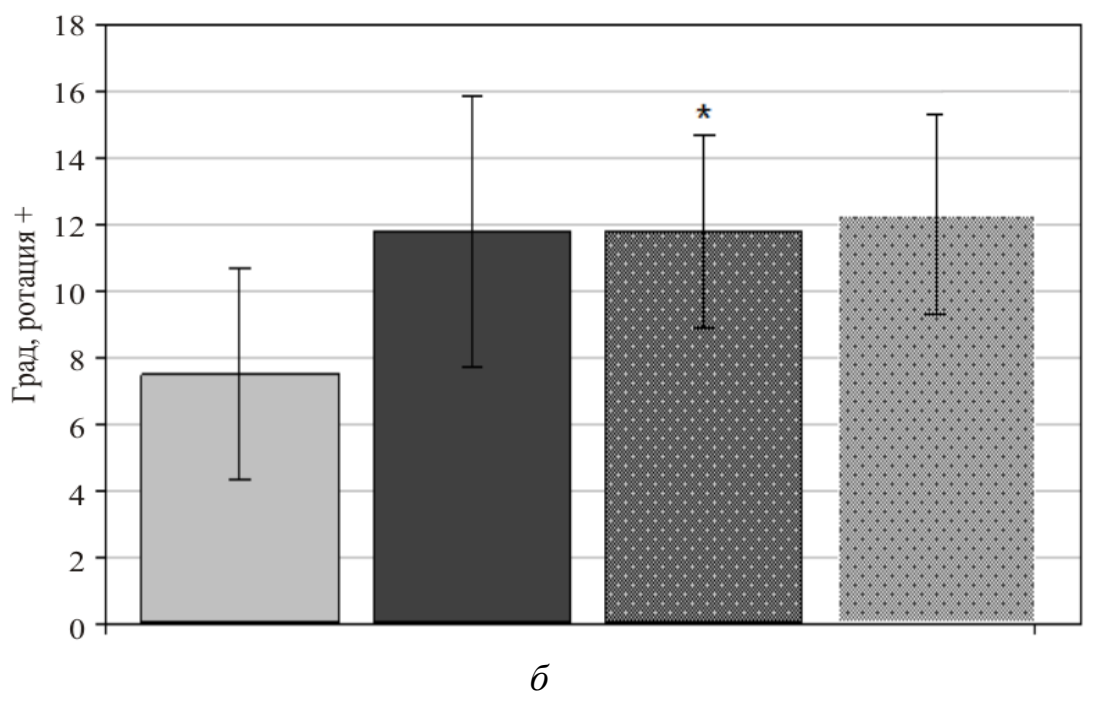




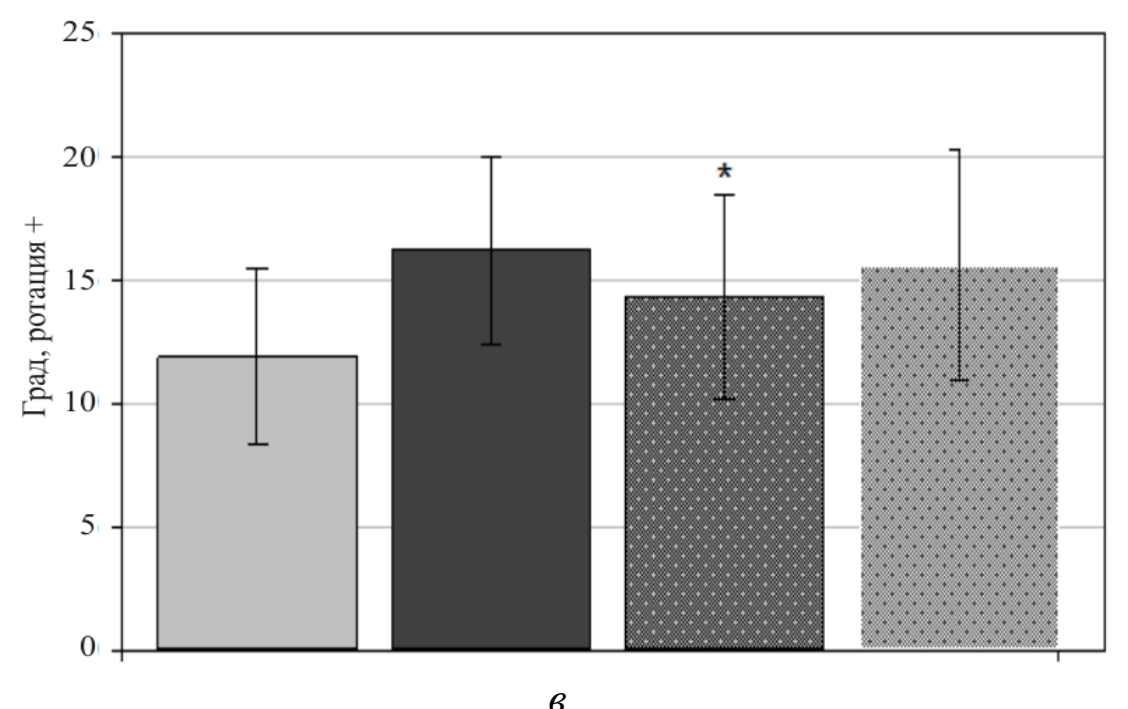

Рис. 4. Угловые позиции тазобедренных суставов в поперечной плоскости: $a-$ начало; $\sigma$ - подъем; $в$ - конец; * - представлены достоверные различия между доминантными конечностями контрольной (КГ) и экспериментальной группами (ЭГ), $p \leq 0,01$. Д - доминантная нижняя конечность; НД - недоминантная нижняя конечность

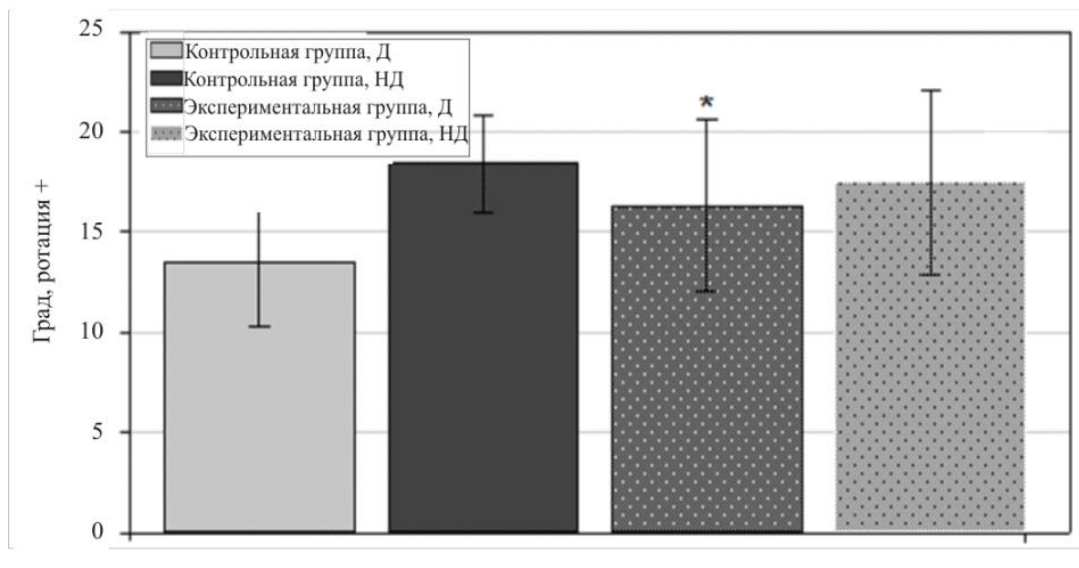

$a$

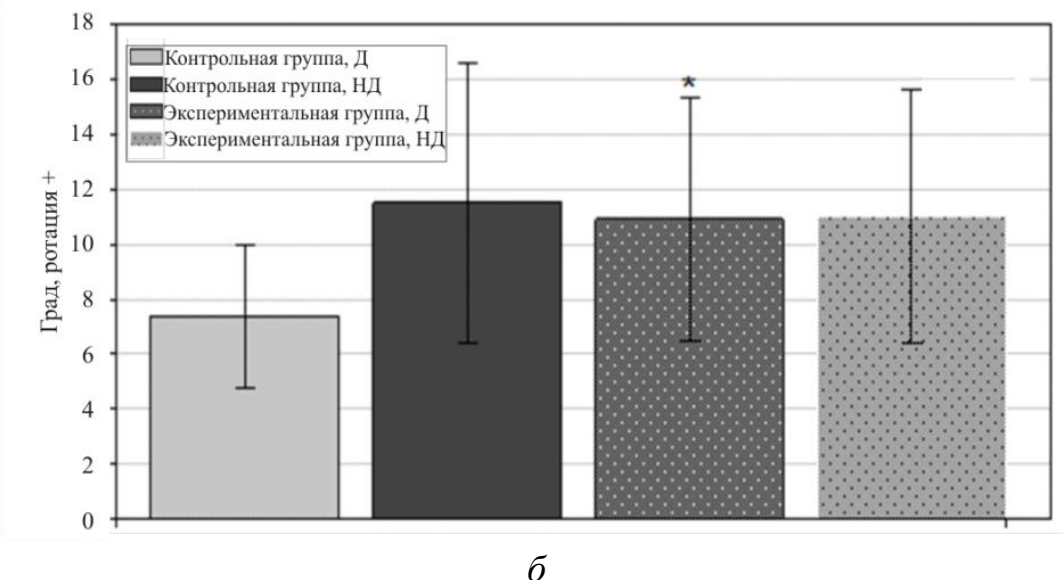

Рис. 5. Угловые позиции тазобедренных суставов в поперечной плоскости: $a-$ максимум; $\sigma$ - минимум; * - представлены достоверные различия между доминантными конечностями контрольной и экспериментальной групп, $p \leq 0,01$.

Д - доминантная нижняя конечность; НД - недоминантная нижняя конечность 


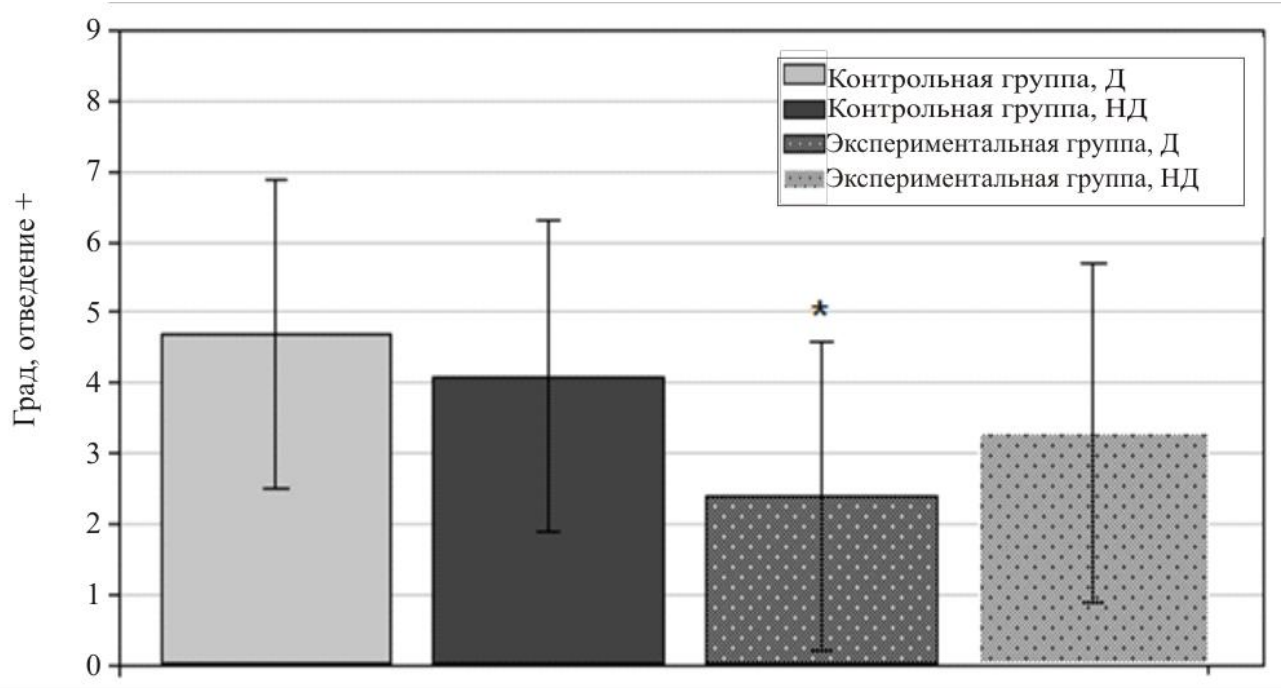

Рис. 6. Угловые позиции тазобедренных суставов в конце теста и при минимальном угловом положении, которое было зафиксировано при выполнении тестового задания, во фронтальной плоскости. * - представлены достоверные различия между доминантными конечностями в контрольной и экспериментальной группах, $p \leq 0,01$. Д - доминантная нижняя конечность; НД - недоминантная нижняя конечность

В поперечной плоскости в экспериментальной группе тазобедренные суставы доминантных конечностей на протяжении всех пяти измеряемых событий (начало, подъем, конец, максимум, минимум) находились в положении бо̉льшей наружной ротации, в то время как тазобедренные суставы испытуемых контрольной группы имели моменты внутренней ротации (рис. 4,5). Во фронтальной плоскости в конце теста и при минимальном угловом положении, которое было зафиксировано при выполнении тестового задания, доминантные конечности испытуемых экспериментальной группы находились в менее отведенном положении, чем доминантные конечности испытуемых контрольной группы (рис. 6).

Помимо различий в кинематике суставов между группами контрольной и экспериментальной, существенные различия также были зафиксированы внутри групп. При статистическом анализе кинематики в тазобедренных суставах у испытуемых контрольной группы в поперечной плоскости на протяжении всех пяти измеряемых событий (начало, подъем, конец, максимум, минимум) недоминантная конечность имела большие моменты наружной ротации, чем доминантная конечность.

\section{ОБСУЖДЕНИЕ}

Авторами зафиксированы существенные различия во времени выполнения тестов между участниками групп контрольной и экспериментальной. Так, экспериментальной группе требуется значительно больше времени на выполнение первой фазы движения (фаза опоры). Среднее время выполнения теста, которое показала экспериментальная группа в нашем исследовании, было меньше, чем время, необходимое испытуемым экспериментальной группы в работе Pai et al. [22]. Более высокую скорость выполнения теста можно объяснить разницей в высоте табурета. Табурет, используемый Pai et al. [22], имел фиксированную высоту, равную 45 см, в то время как высота табурета, использованного в исследовании авторов, регулировалась и составляла $110 \%$ от высоты коленей участников, т.е. $49 \pm 2$ см $($ mean $\pm S D)$. Это было сделано для того, чтобы контролировать разницу в массе тела и длине нижних конечностей. 
Более высокая скорость выполнения теста также могла быть вызвана тем, что участники исследования экспериментальной группы у Pai et al. имели вторую и третью степень остеоартроза, тогда как у участников нашего исследования была первая и вторая степень остеоартроза. Кроме того, в исследовании авторов участники обеих групп были моложе участников исследования Pai et al. [22]. Средний возраст участников нашего исследования у экспериментальной и контрольной групп составлял $56,1(5,8)$ и 51,6 $(7,1)$ г. соответственно (диапазон 41-65 лет), тогда как у Pai et al. 69,6 $(4,6)$ и 70,7 $(5,4)$ г. (mean, SD) (диапазон 64-78 лет). Более продолжительное время выполнения теста напрямую связано с возрастом участников исследования [17].

Существенные различия между группами были зафиксированы и при биомеханическом анализе кинематики тазобедренных суставов во всех трех плоскостях движения. Во время выполнения теста участники экспериментальной группы сгибали бедро с бо́льшим углом, чем участники контрольной группы.

В сагиттальной плоскости существенные различия между группами были зафиксированы лишь в конце цикла движения, что также сочетается с минимальными угловыми моментами, т.е. минимальным сгибанием бедра. Из чего можно сделать вывод, что испытуемые экспериментальной группы сохраняли больший угол сгибания тазобедренного сустава после вставания с табурета. Данное положение может вызвать небольшое смещение центра тяжести туловища вперед и потенциально сократить силу, генерируемую четырехглавыми мышцами для поддержания экстензии колена, таким образом, сократив нагрузку на пателлофеморальный отдел коленного сустава, тем самым уменьшая болевые ощущения в коленном суставе. Недостаток различий между группами в угловых моментах сгибания тазобедренных суставов при подъеме не противоречит результатам исследования Su et al. [26], которые обнаруживали различия лишь тогда, когда высота табурета составляла $65 \%$ от высоты колена. В нашем же исследовании использовался табурет, высота которого составляла $110 \%$ от высоты коленей. Было установлено, что при такой высоте табурета происходит меньшее сгибание бедра и колена [6].

Хотя существенных статистических различий между контрольной и экспериментальной группами в отведении тазобедренных суставов зафиксировано не было, все же тазобедренные суставы участников экспериментальной группы на протяжении всех пяти измеряемых событий были менее отведены, чем тазобедренные суставы участников контрольной группы. Данное положение тазобедренных суставов также имеет тенденцию к увеличению вальгусного вектора четырехглавой мышцы, что способствует увеличению напряжения в хряще коленной чашечки. Авторами также выявлены значительные различия между доминантными и недоминантными конечностями во фронтальной плоскости у участников контрольной группы. Можно высказать предположение, что недоминантные нижние конечности претерпевают значительно большую нагрузку на пателлофеморальный отдел коленного сустава по сравнению с доминантной конечностью. Увеличенная нагрузка на суставную поверхность может быть очень вредна для коленного хряща во время выполнения такого действия, как вставание со стула, так как данное положение требует большей силы сокращения четырехглавой мышцы. Нами также было выявлено, что у испытуемых контрольной группы на протяжении всего цикла вставания недоминантная нижняя конечность находится в положении большей наружной ротации по сравнению с доминантной конечностью, и так как сила, необходимая для сокращения четырехглавой мышцы, напрямую влияет на нагрузку, которую испытывает пателлофеморальный отдел коленного сустава, можно с уверенностью сказать, что в данном случае недоминантные конечности испытуемых контрольной группы находятся в группе риска развития остеоартроза коленного 
сустава. Из чего можно сделать вывод, что измененное положение тазобедренного сустава недоминантной конечности во фронтальной и поперечной плоскостях подвергается большему риску развития остеоартроза в тазобедренном суставе $[5,18]$.

\section{ЗАКЛЮЧЕНИЕ}

При статистической обработке биомеханических показателей контрольной и экспериментальной групп были выявлены существенные различия в кинематике тазобедренных суставов. Установлено, что люди в возрасте от 42 до 65 лет, страдающие остеоартрозом коленного сустава, имеют бо́льшую флексию бедра и бо̉льшие моменты экстензий, отведений и ротаций в тазобедренном суставе. Данные различия могут обозначать, что люди, страдающие от остеоартроза коленного сустава, претерпевают гораздо большее напряжение в хрящах тазобедренного сустава, что потенциально может привести к развитию и/или прогрессированию остеоартроза в тазобедренном суставе. Различия, зафиксированные между доминантной и недоминантной конечностями, могут обозначать, что сила нижних конечностей может также являться модифицирующим фактором, влияющим на напряжение в суставах.

\section{СПИСОК ЛИТЕРАТУРЫ}

1. Беневоленская Л.И., Бржезовский М.М. Эпидемиология ревматических болезней. - М.: Медицина, 1988. - 237 c.

2. Заболеваемость населения России (в 2001-2014 годах): статистические материалы Министерства здравоохранения и социального развития Российской Федерации [Электронный ресурс]. - URL: www.gks.ru/wps/wcm/connect/rosstat_main/rosstat/ru/statistics/population/healthcare/ (дата обращения: 20.05.2015).

3. Anderson J.J., Felson D.T. Factors associated with osteoarthritis of the knee in the first national Health and Nutrition Examination Survey (HANES I). Evidence for an association with overweight, race, and physical demands of work // Am. J. Epidemiol. -1988. - Vol. 128. - P. 179-189.

4. Brandt K.D., Guermazi A., Roemer F.W., Felson D.T. Motion for debate: osteoarthritis clinical trials have not identified efficacious therapies because traditional imaging outcome measures are inadequate // Arthritis Rheum. -2013. - Vol. 65, № 11. -P. 2748-2758.

5. Brian R.U., Lori A.B., Terry R., Timothy L. Comparison of hip and knee strength and neuromuscular activity in subjects with and without patellofemoral pain syndrome // J. Orthop. Sports Phys. Ther. - 2011. Vol. 6, № 4. - P. 285-296.

6. Burdett R.G., Habasevich R., Pisciotta J., Simon S.R. Biomechanical comparison of rising from two types of chairs // Phys. Ther. - 1985. -Vol. 65. - P. 1177-1183.

7. Cicuttini F.M., Teichtahl A.J., Wluka A.E. Frontal plane knee alignment is associated with a longitudinal reduction in patella cartilage volume in people with knee osteoarthritis // Osteoarthritis and Cartilage. 2010. - Vol. 16. - P. 851-854.

8. Cooper C., McAlindon T., Snow S., Vines K., Young K., Young P., Kirwan J., Dieppe P. Mechanical and constitutional risk factors for symptomatic knee osteoarthritis: differences between medial tibiofemoral and patellofemoral disease // Joint Rheumatol. - 1994. - Vol. 21. - P. 307-313.

9. Engebretsen L., Britt E., Holm I. The prevalence of patellofemoral osteoarthritis 12 years after anterior cruciate ligament reconstruction // Knee Surg. Sports Traumatol. Arthrosc. - 2013. - Vol. 21. - P. $942-949$.

10. Elahi S., Cahue S., Felson D.T., Engelman L., Sharma L. The association between varus-valgus alignment and patellofemoral osteoarthritis // Arthritis Rheum. - 2000. - Vol. 43, № 8. - P. 1874-1880.

11. Ellis M.I., Seedhom B.B., Wright V. Forces in the knee joint whilst rising from a seated position // J. Biomed. Eng. - 1984. - Vol. 6. - P. 113-120.

12. Fallah-Yakhdani H.R., Abbasi-Bafghi H. Determinants of co-contraction during walking before and after arthroplasty for knee osteoarthritis // Clin. Biomech. - 2012. - Vol. 27, № 5. - P. 485-494.

13. Fernández-Baena, A., Susín, A., Lligadas, X. Biomechanical validation of upper-body and lower-body joint movements of kinect motion capture data for rehabilitation treatments // Proceedings of the 2012 4th International Conference on Intelligent Networking and Collaborative Systems, 19-21 September 2012. Bucharest, 2012. - P. 656-661.

14. Fulkerson J.P., Edgar C. Medial quadriceps tendon-femoral ligament: surgical anatomy and reconstruction technique to prevent patella instability // Arthrosc. Tech. - 2013. - Vol. 12, № 2. - P. 125-128. 
15. Grelsamer R.P., Weinstein C.H. Applied biomechanics of the patella // Clin. Orthop. Rel. Res. - 2001. Vol. 389. - P. 9-14.

16. Huberti H.H., Hayes W.C. Patellofemoral contact pressures. The influence of Q-angle and tendofemoral contact // J. Bone Joint Surg. - 1984. - Vol. 66. - P. 715-724.

17. Ikeda E.R., Schenkman M.L., Riley P.O., Hodge W.A. Influence of age on dynamics of rising from a chair // Phys. Ther. - 1991. - Vol. 71. - P. 473-481.

18. Ireland M.L., Willson J.D., Ballantyne B.T., Davis I.M. Hip strength in females with and without patellofemoral pain // J. Orthop. Sports Phys. Ther. - 2003. - Vol. 33. - P. 671-676.

19. Lawrence R.C., Felson D.T., Helmick C.G., Arnold L.M., Choi H., Deyo R.A., Gabriel S., Hirsch R., Hochberg M.C., Hunder G.G., Jordan J.M., Katz J.N., Kremers H.M., Wolfe F. Estimates of the prevalence of arthritis and other rheumatic conditions in the United States // Arthritis Rheum. - 2010. - Vol. 58. P. 26-35.

20. Martin C.C., Burkert D.C., Choi K.R., Wieczorek N.B., McGregor P.M., Herrmann R.A., Beling P.A. A real-time ergonomic monitoring system using the Microsoft Kinect // Proceedings of the 2012 IEEE Systems and Information Engineering Design Symposium, 27 April 2012. - Charlottesville, 2012. P. 50-55.

21. McAlindon T.E., Snow S., Cooper C., Dieppe P.A. Radiographic patterns of osteoarthritis of the knee joint in the community: the importance of the patellofemoral joint // Ann. Rheum. Dis. - 1992. - Vol. 51. P. 844-849.

22. Pai Y.-C., Chang H.J., Chang R.W., Sinacore J.M., Lewis J.L. Alteration in multijoint dynamics in patients with bilateral knee osteoarthritis // Arthritis Rheum. - 1994. - Vol. 37. - P. 1297-1304.

23. Schenkman M., Berger R.A., Riley P.O., Mann R.W., Hodge W.A. Whole-body movements during rising to standing from sitting // Phys. Ther. - 1990. - Vol. 70. - P. 638-651.

24. Shao Y., Zhang C. The fate of the remaining nee(s) or hip(s) in osteoarthritic patients undergoing a primary TKA or THA // J. Arthroplasty. - 2013. - Vol. 28, № 10. - P. 1842-1845.

25. Slemenda C., Brandt K.D., Heilman D.K., Mazzucca S., Braunstein E.M., Katz B.P., Wolinsky F.D. Quadriceps weakness and osteoarthritis of the knee // Ann. Intern. Med. - 1997. - Vol. 127. - P. 97-104.

26. Su F.C., Lai K.A., Hong W.H. Rising from chair after total knee arthroplasty // Clin. Biomech. - 1998. Vol. 13. - P. 176-181.

27. Wallace D.A., Salem G.J., Salinas R., Powers C.M. Patellofemoral joint kinetics while squatting with and without an external load // J. Orthop. Sports Phys. Ther. - 2002. - Vol. 32. - P. 141-148.

\section{INFLUENCE OF OSTEOARTHROSIS OF THE KNEE JOINT ON BIOMECHANICAL INDICATORS OF THE HIP JOINT}

\section{R.O. Solodilov, S.I. Loginov (Surgut, Russia)}

Problems of digital visualisation of biomechanical researches of the locomotor system at osteoarthrosis are greatly actual. The aim of research consists in exploring peculiarities of the influence of osteoarthrosis of the knee joint on biomechanical parameters of the hip joint in people at the age of 40-65. In study, 42 people without any symptomatic signs of osteoarthrosis of the knee joint (the control group) and 31 people with bilateral osteoarthrosis of the knee joint (experimental group) at the age of 40-65 took part. With the help of method of markerless motion capture, the significant differences between the control and experimental groups in the kinematics of the hip joints and the time data during the test $(p \leq 0.01)$ were fixed. For making test, experimental group requires $1.94 \pm 0.09$ seconds $(X \pm S D)$, and the control group - only $1.72 \pm 0.07$ seconds $(p \leq 0.01)$. Significant differences were marked during accomplishment of the stance phase where the experimental group spent $0.78 \pm 0.03$ seconds, but the control group $-0.62 \pm 0.03$ seconds $(p \leq 0.01)$. At the 2 nd and 3rd phases, significant differences between the control and experimental groups were not found. It was established that during the test people with osteoarthrosis of the knee have higher hip flexion (by $21 \%$ ) than people without osteoarthrosis of the knee joint. In the control and experimental groups, significant differences were found between dominant lower limbs. In the experimental group, the hip joints of dominant limbs were in a position of more 
external rotation (by $25 \%$ ) in comparison with the control group. Also, it was found that at the end of the test, the hip joints of dominant limbs of the examinees of the experimental group were in less abductive position (by $49 \%$ ) than in the control group. Significant differences between the hip joints of dominant and non-dominant limbs were fixed inside the control group, i.e. non-dominant limb had more moments of external rotation (by $31 \%$ ) than dominant limb $(p \leq 0.01)$. Given differenses can signify that people with osteoarthrosis of the knee joint feel much more stress in the cartilage of the hip joint that can potentially lead to the development and/or advance of osteoarthrosis of the knee in the hip joint.

Key words: biomechanics, osteoarthritis, knee joint, hip joint, markerless motion capture system.

Получено 01 июня 2015 